\title{
Cyclosporine action on kidneys of rats submitted to normothermic ischaemia and reperfusion ${ }^{1}$
}

\author{
Ação da ciclosporina em rins de ratos submetidos à isquemia normotérmica e \\ reperfusão
}

\author{
Adauto José Cologna' ${ }^{\mathrm{I}}$ Lucy Vieira da Silva Lima ${ }^{\mathrm{II}}$, Silvio Tucci Jr. ${ }^{\mathrm{III}}$, Haylton Jorge Suaid ${ }^{\mathrm{III}}$, Rodolfo Borges Reis ${ }^{\mathrm{IV}}$, Luis \\ Fernando Tirapelli , Antônio Antunes Rodrigues Jr. ${ }^{\text {VI }}$, Antonio Carlos Pereira Martins ${ }^{\mathrm{VII}}$ \\ I MD, PhD, Division of Urology, Department of Surgery and Anatomy, Ribeirão Preto Faculty of Medicine, University of São Paulo, \\ Brazil. \\ ${ }^{\text {II }} \mathrm{MD}, \mathrm{PhD}$, Associate Professor, Federal University of Alagoas, Brazil.

 \\ University of São Paulo, Brazil. \\ ${ }^{\text {IV }}$ MD, PhD, Division of Urology, Department of Surgery and Anatomy, Ribeirão Preto Faculty of Medicine, University of São Paulo, \\ Brazil. \\ v MD, PhD, Department of Surgery and Anatomy, Ribeirão Preto Faculty of Medicine, University of São Paulo, Brazil. \\ ${ }^{\mathrm{VI}} \mathrm{MD}$, Fellow PhD degree, Division of Urology, Department of Surgery and Anatomy, Ribeirão Preto Faculty of Medicine, University of \\ São Paulo, Brazil.

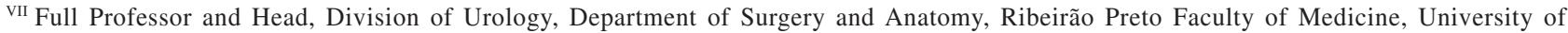 \\ São Paulo, Brazil.
}

\begin{abstract}
Purpose: To verify if rat kidneys lesioned by ischaemia followed by reperfusion are affected by cyclosporine A (CsA). Methods: Male Wistar rats were randomly divided into three groups, control (GS) and experimental (G1 and G2). G1 was subdivided in two: G1A composed of animals submitted to 60 minutes ischaemia and G1C with the same ischaemic procedure associated to $20 \mathrm{mg} / \mathrm{kg} / \mathrm{day}$ CsA. Group G2 was subdivided and treated in the same way as G1 except that ischaemia was applied only for 40 minutes. Clamping the left renal artery followed by right side nephrectomy induced kidney ischaemia. Serum urea and creatinine were quantified on the day of surgery (D0) and in the following day (D1). Twenty four hours after reperfusion the left kidney was removed and histologically analyzed. Results: Group GS had normal values for urea and creatinine both on D0 and D1 and did not show structural alterations. Renal function was not significantly different when G2C was compared to GS ( $p>0.05$ ). Tissue lesions were smaller in G2C than in the other groups. Conclusions: Renal function was protected by CsA, which also reduced tissue lesions in the kidneys of rats submitted to 40 minutes ischaemia.
\end{abstract}

Key words: Cyclosporine. Kidney. Ischaemia/Reperfusion.

\section{RESUMO}

Objetivo: Verificar se a ciclosporina A (CsA) afeta a lesão provocada pela isquemia seguida de reperfusão em rins de ratos. Métodos: Ratos Wistar machos foram separados em grupos: 1 grupo controle (GS) e 2 grupos experimentais (G1 e G2). O G1 foi dividido em G1A - isquemia de 60 minutos; e G1C - isquemia de 60 minutos associada a $20 \mathrm{mg} / \mathrm{kg} / \mathrm{dia}$ de CsA. O G2 foi dividido em $\mathrm{G} 2 \mathrm{C}$ semelhante ao $\mathrm{G} 1$, exceto pelo tempo de isquemia de 40 minutos. A isquemia renal foi provocada pelo pinçamento da artéria renal esquerda, após o procedimento, foi realizada a nefrectomia direita. Dosagem de uréia e creatinina séricos foram feitos no dia da cirurgia (D0) e no dia seguinte (D1). Após 24 horas de reperfusão o rim esquerdo foi removido para análise histológica. Resultados: No GS não foram observados alterações de uréia e creatinina em D0 e D1, tampouco alterações estruturais. A comparação entre GS e G2C não mostrou diferença na função renal ( $p>0,05$ ); o grau de lesão tecidual foi menor em G2C do que nos demais grupos experimentais. Conclusão: ACsA protegeu a função renal e reduziu a lesão tecidual em rins de ratos submetidos a 40 minutos de isquemia.

Descritores: Ciclosporina. Rim. Isquemia/Reperfusão.

1. Study conducted at the Laboratories of Experimental Surgery, Biochemistry and Histology, Sector of Surgical Techniques and Experimental Surgery in the Department of Surgery and Anatomy, Ribeirão Preto Faculty of Medicine, University of São Paulo, Brazil. 


\section{Introduction}

Some clinical-surgical procedures as kidney transplant, by-pass processes, renal angioplasty and clamping of the renal pedicle or the aorta above the renal arteries are frequent urological or vascular events and require temporary interruption or reduction of the renal perfusion flux. In these instances, disorders known as perfusion lesions are superimposed on the ones produced by ischaemia itself resulting in injury or lack of viability to organs, native or grafted. ${ }^{1}$

The alterations, whose mechanisms are still not understood, include microvascular dysfunction, ${ }^{2-4}$ activation of the tumoral necrosis factor, ${ }^{5}$ and oxidative stress. ${ }^{6}$ As a consequence of renal ischaemia, acute renal insufficiency is installed and dysfunctional renal grafts may suffer early losses, launched in this case by factors other than antigenic.?

Particularly, in cases of renal transplants immunosuppressive drugs employed to control immune responses could have a role in the events caused by ischaemia/reperfusion. Although most research work is directed to the understanding of nephrotoxicity, some try to elucidate mechanisms of renal protection against injury caused by ischaemia by adjusting, for example, cyclosporine A (CsA) dosages during the critical period of renal flux interruption which is present during transplants. ${ }^{8-10}$ However, the practice is controversial since some authors report renal lesion worsening and organ dysfunction by CsA use ${ }^{11}$ and others claim a protective effect, even suggesting its use in low dosages as a pharmacological pre-conditioning. ${ }^{9}$

The aim of this study was to verify the effect of CsA in kidneys of rats submitted to ischaemia and reperfusion (I/R) and try to answer the following question: Is CsA able to modify the I/R lesion on functional and structural grounds?

\section{Methods}

Male Wistar rats weighing around 200-300g and raised at the Central Animal House of the Faculty of Medicine of Ribeirão Preto, University of São Paulo (FMRPUSP) were randomly divided in three groups, GS (control) and G1 and G2 (experimental) and kept at the Laboratory of Experimental Surgery, Biochemistry and Histology in the Technical Sector of Experimental Surgery, Department of Surgery and Anatomy (FMRP-USP).

Animals in the three groups were treated according to the following general protocol: the GS group animals $(n=6)$ were submitted to laparotomy, blood collection, exposure of the left renal pedicle and kept anesthetized during a time corresponding to the minimal surgery duration, followed by right nephrectomy. Groups G1 and G2 ( $n=12$ each) were divided into two subgroups, G1A and G1C and $\mathrm{G} 2 \mathrm{~A}$ and $\mathrm{G} 2 \mathrm{C}(\mathrm{n}=6)$ respectively. In subgroup $\mathrm{G} 1 \mathrm{~A}$, after the same initial procedures animals were submitted to 60 minutes normothermic ischaemia followed by 24 hours reperfusion; Group G1C was treated in the same way except that the animals received CsA. In subgroups $\mathrm{G} 2 \mathrm{~A}$ and $\mathrm{G} 2 \mathrm{C}$, the ischaemic time duration was only 40 minutes and all the other procedures were similar to Groups G1 A and C.

Cyclosporine $A \circledR$ used was from ampoules of $1 \mathrm{ml}$ containing 50mg of the drug diluted with physiological saline and applied in $20 \mathrm{mg} / \mathrm{kg} /$ day dosages by the i.p. route, 24 hours before and on the day of surgery, as described.

Briefly, animals were anesthetized i.p. by $50 \mathrm{mg} / \mathrm{kg}$ sodium pentobarbital before medial longitudinal laparotomy and exposure of the inferior vena cava, below the renal vessels, for blood collection and serum determinations of day zero (D0) urea and creatinine. The left renal pedicle was then exposed, and the renal artery isolated soon after the aorta emergence with the help of a $2.5 x$ magnifying glass. Ischaemia was produced by occlusion of the left renal artery with non traumatic vascular steel mini tweezers (bulldog). Change in the tissue color and lack of renal arterial pulsation indicated successful ischaemia. After 40 or 60 minutes (Groups G2 or G1) the tweezers were removed and once reperfusion was established (tissue normal color and renal artery pulse returned and permeable renal vein) right nephrectomy was performed and the abdominal cavity closed. During the full surgical procedure animals were kept at an environmental temperature of $37^{\circ} \mathrm{C}$, allowing their body temperature to remain at $36.5^{\circ} \mathrm{C} \pm 0.5$ as at the start of surgery (verified by a rectal type digital thermometer).

After 24 hours perfusion, new anesthesia and reopening of the abdominal cavity, blood samples were collected from the inferior vena cava for D1 determinations of serum urea and creatinine and the left kidney removed, fixed in neutral formalin in $10 \%$ buffer and paraffin-included. Kidney histological analysis was made through an optical microscope with 10, 200 and 400x magnifications.The lesions observed were graded from 0 to $4 .{ }^{12}$

Statistical analyses were performed with the software program GraphPad Prism 4 (GraphPad Software Inc. San Diego, CA, USA). Continuous variables were compared by double tail two-way Anova and the TukeyKramer multiple comparisons test the level of significance was fixed in $1 \%$.

\section{Results}

Renal function was evaluated by serum urea and creatinine determined on all animals on the day of surgery (D0) and 24 hours after (D1). Mean values \pm SD are shown in Tables 1 and 2, respectively. 
TABLE 1 - Serum urea values in the blood of animals of the different groups determined on $\mathrm{D} 0$ and $\mathrm{D} 1$.*Means $\mathrm{X} \pm \mathrm{SD}$.

\begin{tabular}{|c|c|c|c|c|c|c|c|}
\hline & & & GS & G1A & G1C & G2A & G2C \\
\hline \multirow[t]{2}{*}{ Urea } & $\bar{X}$ & & 58.16 & 59 & 44.5 & 51.5 & 58 \\
\hline & D0 & $\mathrm{SD}$ & 12.22 & 4.19 & 5.85 & 5.64 & 8.6 \\
\hline \multirow{2}{*}{ Urea } & $X$ & & 55.5 & 390 & 243.16 & 275.5 & 86.16 \\
\hline & D1 & SD & 5.85 & 21.41 & 104.56 & 145.57 & 17.5 \\
\hline
\end{tabular}

*Sandimum ${ }^{\circledR}$, Laboratories Novartis Co. Brazil -Switzerland.

TABLE 2 - Serum creatinine values in the blood of animals of the different groups determined on D0 and D1. Means X \pm SD.

\begin{tabular}{cccccc}
\hline & GS & G1A & G1C & G2A & G2C \\
\hline Creatinine $\bar{X}$ & 0.51 & 0.68 & 0.56 & 0.068 & 0.71 \\
D0 SD & 0.07 & 0.07 & 0.05 & 0.13 & 0.04 \\
Creatinine $\bar{X}$ & 0.7 & 4.66 & 3.08 & 2.6 & 1.1 \\
D1 SD & 0.1 & 0.37 & 0.67 & 1.4 & 0.17 \\
\hline
\end{tabular}

Urea and creatinine results in D0 for all groups did not show significant differences.

In D1, however, urea values were significantly increased in Groups 1 and 2 when compared to the control $\mathrm{GS}(\mathrm{p}<0.001)$ except for $\mathrm{G} 2 \mathrm{C}(\mathrm{p}>0.05)$. Comparing groups submitted to 60 minutes ischaemia, G1A x G1C, the difference in the mean urea values were significant $(\mathrm{p}<0.01)$.
The same correlation was seen when comparing group G2 (40 minutes ischaemia) subgroups, G2A xG2C on D1 ( $\mathrm{p}<0.01$ ). In both cases urea values were smaller in subgroups $\mathrm{C}$, that is in the presence of CsA. Comparison of G2A mean urea value (40 minutes ischaemia) with the one in $\mathrm{G1C}$ (60 minutes ischaemia plus CsA) was not significant ( $\mathrm{p}>0.05$ ) (Table 3 ).

TABLE 3 - Comparison of mean urea values determined in D1 for groups and control. Confidence intervals CI $(95 \%)$ and $\mathrm{p}$ values.

\begin{tabular}{lcrrr}
\hline \multirow{2}{*}{ Groups Compared } & \multirow{2}{*}{$\mathrm{P}$} & \multicolumn{3}{c}{ CI (95\%) } \\
\cline { 3 - 5 } & & \multicolumn{1}{c}{ From } & \multicolumn{1}{c}{ To } \\
\hline GSxG1A & $\mathrm{p}<0.001$ & -447.63 & $;$ & -221.37 \\
GSxG1C & $\mathrm{p}<0.001$ & -300.8 & $;$ & -74.53 \\
GSxGA & $\mathrm{p}<0.001$ & -333.13 & $;$ & -106.87 \\
GSxG2C & $\mathrm{p}<0.05$ & -148.8 & $;$ & 82.46 \\
G1AxG1C & $\mathrm{p}<0.01$ & 33.59 & $;$ & 259.97 \\
G2AxG2C & $\mathrm{p}<0.01$ & 76.1 & $;$ & 302.47 \\
G1CxG2A & $\mathrm{p}>0.05$ & -80.8 & $;$ & -145.47 \\
G1AxG2C & $\mathrm{p}<0.05$ & -227.63 & $;$ & -1.36 \\
\hline
\end{tabular}

Comparing mean creatinine values determined on D1 shows significant differences in Groups 1 and 2 when compared to GS ( $\mathrm{p}<0.001)$ except for G2C x GS ( $p>0.05) \mathrm{G} 1$ and G2 subgroups, G1A x G1C and G2A x G2C, show significant differences in mean creatinine values $(p<0.001)$ and in both cases values determined in the presence of CsA are smaller. There is no significant difference when comparing G2A x G1A in relation to the mean creatinine values in D1 $(\mathrm{p}<0.05)$ (Table 4). 
TABLE 4 - Comparison of mean creatinine values determined in D1 for groups and control. Confidence intervals CI (95\%) and p values.

\begin{tabular}{lcrcc}
\hline \multirow{2}{*}{ Groups Compared } & $\mathrm{P}$ & \multicolumn{3}{c}{ CI $(95 \%)$} \\
\cline { 3 - 4 } & & From & To \\
\hline GSxG1A & $\mathrm{p}<0.001$ & -4.97 & -2.95 \\
GSxG1C & $\mathrm{p}<0.001$ & -2.38 & -3.39 \\
GSxG2A & $\mathrm{p}<0.001$ & -2.91 & $;$ & -0.88 \\
GSxG2C & $\mathrm{p}>0.05$ & -1.41 & $;$ & 0.61 \\
G1AxG1C & $\mathrm{p}<0.01$ & 0.57 & 2.59 \\
G2AxG2C & $\mathrm{p}<0.001$ & 0.48 & $;$ \\
G1CxG2A & $\mathrm{p}>0.05$ & -0.52 & $; .51$ \\
G1AxG2A & $\mathrm{p}<0.05$ & 1.05 & $; .49$ \\
\hline
\end{tabular}

Histological evaluation of kidney lesions in the animals of all groups was according to the Jablonski et al. $(1983)^{12}$ classification and graded from 0 to 4 . More extensive lesions, grade 4, were seen in groups G1A, G1C and G2A; G2C had less extensive lesions (Table 5).

TABLE 5 - Distribution of lesion grades in the control and experimental groups, according to the classification by Jablonski et al. (1983).

\begin{tabular}{lccccc}
\hline Grade & \multicolumn{5}{c}{ Animal Groups } \\
\hline 0 & GS & G1A & G1C & G2A & G2C \\
1 & 4 & - & - & - & - \\
2 & 2 & - & - & - & 2 \\
3 & - & - & 2 & - & 3 \\
4 & - & 2 & - & 2 & 1 \\
\hline
\end{tabular}

Comparisons between G1A x G1C, G1A x G2A and G1C x G2A did not show significant differences. G2A and $\mathrm{G} 2 \mathrm{C}$ were different with a $\mathrm{p}<0.01$. GS animals were practically lesion-free and the comparison of this group with the others was highly significant as to the lesion level (Table 6).

TABLE 6 - Comparison of histological grade levels of lesions in all groups. Confidence intervals, CI (95\%) and p values.

\begin{tabular}{lcccc}
\hline \multirow{2}{*}{ Groups Compared } & $\mathrm{P}$ & \multicolumn{3}{c}{ CI (95\%) } \\
\cline { 3 - 5 } & & From & To \\
\hline GSxG1A & $\mathrm{p}<0.001$ & -4.51 & -2.15 \\
GSx G1C & $\mathrm{p}<0.001$ & -4.18 & -1.81 \\
GSx G2A & $\mathrm{p}<0.001$ & -4.51 & -2.15 \\
GSxG2C & $\mathrm{p}<0.01$ & -2.68 & -0.31 \\
G1AxG1C & $\mathrm{p}>0.05$ & -0.85 & $; .51$ \\
G1AxG2A & $\mathrm{p}>0.05$ & -1.18 & $; .18$ \\
G1AxG2C & $\mathrm{p}<0.01$ & -0.64 & $;$ & 3.01 \\
G1CxG2A & $\mathrm{p}<0.05$ & -1.51 & $;$ & 0.85 \\
G1CxG2C & $\mathrm{p}<0.01$ & 0.31 & $;$ & 2.68 \\
G2AxG2C & $\mathrm{p}<0.01$ & 0.64 & $;$ & 3.01 \\
\hline
\end{tabular}




\section{Discussion}

The overall analysis of the results obtained in this study shows that with the exception of the control group, GS, all interventions involved some level of dysfunction or structural kidney alterations, which progressed from less intense as observed in Group 2 ischaemia for 40 minutes to more extensive as in the 60 minutes ischaemia, Group 1. Although the results in general confirm literature reports, ${ }^{12-}$ 14 there are discrepancies in this study when compared to Jablonski et al. $1983^{12}$ as to the severity of the renal lesions. The favorable results in the earlier study may have been affected by the use of heparin, during surgery and the ischaemia period, due to its antithrombin effect. Like heparin, other factors as anesthetics and animal temperatures may influence the results. Anesthetics could alter colateral organ circulation and among the ones most used in experimental studies, pentobarbital shows the best behavior. ${ }^{14}$

Temperature control is also important in investigations related to ischaemia. ${ }^{14,15}$ Lower environmental temperature affect animal body temperatures, significantly decreasing energy demand and oxygen consumption, which contributes to the decrease of tissue lesions. ${ }^{16}$

Determinations of serum urea and creatinine, as a measure of the efficacy of kidney protection procedures, show that the basic ones-anesthesia, laparotomy, CsA pretreatment- did not cause alterations in these parameters. This conclusion is based on the values obtained before and after procedures in the GS group and the other individual dosages determined in D0. The knowledge that the first alterations in urea and creatinine levels occur when kidney function is compromised in above $50 \%$, indicates the probability of lesion occurence in all experimental groups, independent of the procedure utilized..$^{17}$

The urea and creatinine results in this study show that the lesions were more severe when the blood flux was interrupted for 60 minutes although this effect tended to be reduced in the presence of CsA (groupG1C). A similar tendency is indicated in the comparison of groups G2A and G2C. Values for urea and creatinine for G2C (40 minutes ischaemia plus CsA) were significantly different from GS, considering that the interruption time was superior to 30 minutes, the time established for the occurrence of minor lesions. ${ }^{12}$ Other authors, using 45 minutes ischaemia and smaller CsA dosages obtained similar results. ${ }^{8}$ On the other hand, rats submitted to 60 minutes ischaemia associated to $10 \mathrm{mg} / \mathrm{kg} /$ day CsA showed higher levels of creatinine and urea than the ones submitted to I/R only during the same period $^{10}$, in contrast to the earlier results, which always showed improvement in the presence of CsA. Other studies reinforce these findings, demonstrating that CsA dosages of $1.5 \mathrm{mg} / \mathrm{kg} / \mathrm{day}$ and 0.01 and $100 \mathrm{mg} / \mathrm{ml}$ respectively, in situ in the kidney and in isolated tubule cells, did not affect the renal function or the proximal tubular epithelial cell viability. ${ }^{18,19}$

Other reports indicate the protective effect of CsA on the ischaemic kidney, suggesting low doses as a pharmacological pre-conditioning. ${ }^{9}$ This novel approach, which in a way contradicts nephrotoxic established concepts is attracting interest in the use of the drug in low dosages. ${ }^{8,10,20}$ The CsA dose, $20 \mathrm{mg} / \mathrm{kg} / \mathrm{day}$, utilized in this study may be considered intermediate in its capacity to induce functional alterations and low in relation to the dose of $100 \mathrm{mg} / \mathrm{kg} /$ day capable to produce renal tubule lesions in rats. ${ }^{17}$

In relation to histological alterations, animals submitted to 40 minutes ischaemia in the presence of CsA (G2C) showed the least severe lesions in all experimental groups indicating a drug protective effect, which disappeared when flux interruption was extended to 60 minutes.

\section{Conclusion}

Cyclosporine A protected the renal function and reduced the severity of the kidney tissue lesions subjected to 40 minutes normothermic ischaemia followed by reperfusion.

\section{References}

1. Land W. Postischemic reperfusion injury and allograft dysfunction: Is allograft rejection the result of fatefull confusion by the immune system of danger and benefit? Transplantation Proceedings. 1999;31:332-6.

2. Semenza GL. Cellular and molecular dissection of reperfusion injury. ROS within and without. Circulation Research. 2000;86:117-21.

3. Carden DL, Grager DN. Pathophysiology of ischaemia-reperfusion injury. Journal of Pathology. 2000;190:255-66.

4. Évora PR, Pearson PJ, Seccombe JF, Chaff HV. Lesão de isquemia-reperfusão. Aspectos fisiopatológicos e a importância da função endotelial. Arquivo Brasileiro de Cardiologia. 1996;66:239-52.

5. Donnahoo KK, Meldrum DR, Shenkar R, Chung C-S, Abraham E, Harker AH. Early renal ischeamia, with or without reperftusion, activates $\mathrm{NF}_{\mathrm{k}} \mathrm{B}$ and increases TNF-. bioactivity in the kidney. The Journal of Urology. 2000;163:1328-32.

6. Li C, Jackson RM. Reactive species mechanisms of cellular hypoxiareoxygenation injury. American Journal of Cell Physiology. 2002;282:227-41.

7. Tullius SG, Tilney NL, Both allantigen-dependent and independent factors influence chronic allograft rejection. Transplantation. 1995;59:2138.

8. Woo Yang C, Jong Ahn H, Joon Han H, Young Kim W, Li C, Jung Shin M. Pharmacological preconditioning with low-dose cyclosporine or FK506 reduces subsequent ischaemia/reperfusion injury in rat kidney. Transplantation. 2001;72:17539.

9. Cattaneo D, Perico N, Gaspari F, Remuzzi G. Nephrotoxic aspects of Cyclosporine. Transplantation Proceedings. 2004;36(Suppl 2S):234S-9.

10. Ysebaert DK, De Greef KE, Nouwen EJ, Verpooten GA, Eyskenns EJ, De Broe ME. Influence of cyclosporine $\mathrm{A}$ on the damage and regeneration of the kidney after severe ischaemia/reperfusion injury. Transplantation Proceedings. 1997;29:234851 .

11. Ysebaert DK, De Greef, Vercauteren SR, Verhulst A, Kockx M, Verpooten GA, De Broe ME. Effect of immunosuppression on damage, leukocyte infiltration, and regeneration after severe warm 
ischaemia/reperfusion renal injury. Kidney International. 2003;64:864-73.

12. Jablonski P, Howden BO, Rae DA, Birrell CS, Marshall VC, Tange J. An experimental model for assessement of renal recovery from warm ischaemia. Transplantation. 1983;35:198-4.

13. Torras J, Herrero-Fresneda I, Lloberas N, Riera M, Cruzado JM, Grinyó. Promising effects of ischaemia preconditioning in renal transplantation. Kidney International. 2002;61:2218-27.

14. Ross S, Foex P. Protective effects of anaesthetics on reversible and irreversible ischaemia-reperfusion injury. British Journal of Anaesthesia. 1999;829:622-32.

15. Heijnen BHM, Van Veen SQ, Straatsburg IH, Thomas MVG. Pronounced effect of minor changes in body temperature on ischaemia and reperfusion injury in rat liver. Journal Applied Physiology. 2001;91:265-8.
16. Levy MN. Oxygen consumption and blood flow in the hypothermic perfused kidney. American Journal Physiology. 1959;197:111-3.

17. Garcia TMP. Avaliação dos efeitos nefrotóxicos causados pela ciclosporina $\mathrm{A}$ em ratos através do estudo dinâmico renal com 99mTC-MAG3. [Tese Doutorado]. Universidade de São Paulo - FMRPUSP; 1995.

18. Bakker RC, Kooten C, Lagemaat-Paap Me, Daha MR, Paul LC. Renal tubular epithelial cell death and cyclosporine A. Nephrology Dialyasis Transplantation. 2002;17:1181-8.

19. Zhu T, Au-Yeng KKW, Siow YL, Wang G, Karmin O. Cyclosporine A protects against apoptosis in ischaemia/reperfused rat kidneys. Clinical an Experimental Pharmacology an Physiology. 2002;29:852-4.

20. Singh D, Chander V, Chopra K. Cyclosporine protects against ischaemia/reperfusion injury in rat kidneys. Toxicology. 2005,207:339-41.

\author{
Correspondence: \\ Adauto J. Cologna \\ Department of Surgery and Anatomy \\ Ribeirão Preto Faculty of Medicine, University of São Paulo \\ 14.048-900 Ribeirão Preto, São Paulo, Brazil. \\ ajcologn@fmrp.usp.br
}

Conflict of interest: none Financial support: FAEPA

\title{
How to cite the article:
}

Cologna AJ, Silva Lima LV, Tucci Jr. S, Suaid HJ, Reis RB, Tirapelli LF, Rodrigues Jr AA, Martins ACP. Cyclosporine action on kidneys of rats submitted to normothermic ischaemia and reperfusion. Acta Cir Bras. [serial on the Internet] 2008; 23 Suppl 1. Available from URL: http://www.scielo.br/acb.

\section{Comments:}

Occurrence of ischaemia and reperfusion is encountered in several conditions where the renal blood flow is interrupted, as in renal transplants. Cyclosporine $\mathrm{A}$, one of the main drugs used in transplants is also associated to renal nephrotoxicity. Cologna et al. evaluated the effects of cyclosporine A in rats submitted to normothermic ischaemia and reperfusion during 40 or 60 minutes. Evaluating the renal function by serum urea and creatinine and by morphological parameters, the authors concluded that the lesions produced in the shorter time ischaemia (40 minutes) were less severe. It was concluded that in this experimental model, $20 \mathrm{mg} / \mathrm{kg} /$ day cyclosporine had a nephroprotector effect. The results are interesting and somewhat different of the expected, since part of the nephrotoxic effect of cyclosporine itself is due to decrease of renal blood flow. These are preliminary results that should be reproduced and have the functional studies improved by results of measurements of renal blood flow and inulin clearance. These more precise methods would furnish important information on the mechanisms involved in the reported results, as a possible improvement in the renal blood flow. In future studies, oxidative stress and other cellular biology parameters could be evaluated morphometrically. Apoptosis intensity could be an alternative evaluation of the renal lesion severity besides contributing to explain the ways involved with the alterations shown.

\section{Marcio Dantas}

MD, PhD, Nephrology Division, Department of Clinical Medicine, Ribeirão Preto Faculty of Medicine, University of Sao Paulo, Brazil.

\section{Comments:}

The main objective of the authors was to assess whether immunosuppression with cyclosporin A(CsA) interferes with the renal injuries caused by ischaemia and reperfusion (I/R) that commonly occur in renal transplant procedures. Using an elegant experimental model, they tested the effect of CsA on the kidneys of rats submitted to I/R, and its possible nephrotoxic effect. They concluded that CsA, in general, reduces the tissue injury during the period of ischaemia. The present study is important by expanding the knowledge about the physiopathology of the injury caused by I/R and its interaction with immunosuppression, situations frequently occurring in renal transplantation.

\section{Orlando de Castro-e-Silva}

Full Professor and Head, Division of Digestive Surgery, Department of Surgery and Anatomy, Ribeirão Preto Faculty of Medicine, Brazil. 